\title{
Managing acute hypercapnic respiratory failure in adults: where do we need to get to?
}

\author{
A Craig Davidson, On Behalf of the British Thoracic Society Guideline \\ Group For The Ventilatory Management of Acute Hypercapnic \\ Respiratory Failure in Adults
}

\section{RATIONALE FOR A NEW GUIDELINE FOR THE VENTILATORY \\ MANAGEMENT OF ACUTE HYPERCAPNIC RESPIRATORY FAILURE IN ADULTS}

The concept of augmenting spontaneous breathing effort by a close fitting face mask has evolved from initial case reports, nearly two decades ago, to become part of mainstream acute clinical care. Indeed, it has become the preferred option to invasive ventilation in many cases of acute hypercapnic respiratory failure (AHRF). In the UK, service development has been driven largely by respiratory physicians and this has resulted in an unintended, and unhelpful, dichotomy of responsibility for patient care. NIV guidelines that have been published have, by being concerned with the practicalities of delivery of a new service, failed to promote appropriate integration between those providing the acute NIV service and intensivists, the gate keepers to the intensive care unit (ICU) and who manage the invasively ventilated patient. The joint British Thoracic Society (BTS) and Intensive Care Society guideline for 'the ventilatory management of acute hypercapnic respiratory failure in adults', a supplement to this edition of Thorax, instead aims to promote shared clinical responsibility and reviews the evidence base for both invasive and NIV in the variety of conditions that may present as AHRF.

\section{MEETING THE GOALS OF THE GUIDELINE}

Hypercapnic respiratory failure is less common than hypoxic respiratory failure but is still a frequent cause of emergency hospital admission. It complicates around $20 \%$ of acute exacerbations of COPD (AECOPD), signalling advanced disease, a high risk of future hospital admission and limited long-term prognosis. Its presence increases the mortality of an exacerbation

Correspondence to Dr A Craig Davidson, Vine House, Dartmouth, Devon, TQ6 9NW, UK; craigandfrankie@gmail.com from $8 \%$ to as much as $30 \%$, depending on the degree of respiratory acidosis. ${ }^{1}$ Morbid obesity is now the second most common cause of AHRF and has become the leading indication for initiating domiciliary NIV. Other causes, including asthma, bronchiectasis, cystic fibrosis and the restrictive conditions, such as chest wall deformity, motor neurone disease and muscular dystrophy, also contribute to an estimated 50000 AHRF admissions per annum. This is a similar number to those admitted with acute upper gastrointestinal haemorrhage which, quite rightly, is recognised as a medical emergency that requires coordination of care between different teams and where delay in instituting treatment also increases mortality. $^{2}$

Despite the importance of managing AHRF appropriately, and in a timely fashion, evidence has accumulated demonstrating that many patients do not currently receive optimal treatment. The provision of NIV is often poorly resourced and fails to deliver expected patient benefit. Most patients only receive NIV treatment when the respiratory acidosis has become very severe and some appear to be inappropriately denied admission to the ICU. ${ }^{1}{ }^{3-5}$ Despite the severity of illness, the majority of NIV patients are currently managed on general admission or medical wards and there is often no involvement of the critical care team. ${ }^{45}$ This is further confounded, as the British Thoracic Society audit data have shown, by inappropriately low inflation pressures being employed, a lack of responsiveness to clinical problems that develop and little evidence for documentation or escalating care when NIV fails. ${ }^{4-6}$

\section{VENTILATORY MANAGEMENT OF THE ADULT PATIENT WITH HYPERCAPNIC RESPIRATORY FAILURE}

Until the development of NIV, intubation was required to manage patients failing to improve with conventional medical treatment. It is unclear what criteria guided recognition of this need and historically it seems invasive ventilation was variably offered to such patients, an observation made in the UK and across Europe. An important aspect in the development of NIV was the demonstration that it delayed progression to more severe hypercapnia and worsening respiratory acidosis ${ }^{7}$ as well as identifying prognostic factors in patients with an acute exacerbation of COPD. As might be expected, outcome is less good in those with specific adverse features and especially when multiple. ${ }^{1}$

Disappointingly and despite the availability of severity scoring, clinicians appear to consistently underestimate survival potential. ${ }^{8}$ The perceived hospital culture, which influences the intensity of the care delivered, combined with the limited availability of ICU beds may also have played a role in clinical decision-making regarding admission to the ICU. ${ }^{9}$ This is at odds with the recognition of the importance of patient involvement in care planning ${ }^{10}$ that make it vitally important that potentially life-saving treatment, such as intubation or NIV, is not inappropriately withheld.

\section{IMPLEMENTATION OF THE GUIDELINES}

If, as the guideline supports, UK hospitals are to respond to the challenge of providing equitable care in AHRF there are significant resource implications. For instance, in AECOPD, the severity of acidosis, with or without other clinical complications, will make invasive mechanical ventilation necessary in about $25 \%$ of cases (including those failing with NIV) yet many are currently denied admission to the ICU. ${ }^{34}$ In the non-COPD causes of AHRF, invasive ventilation may still offer a better chance of survival than NIV and the guideline usefully reviews the additional management issues found in these conditions, the current lack of high quality evidence and the particular need for multi-professional consultation and care. The guideline also makes the case that ICU admission is advisable in many non-COPD cases because NIV failure is either more likely than in AECOPD or because intubation, if required, may be expected to be difficult. Taken together, this suggests that full implementation of the guideline recommendations will require increasing the UK critical care capacity to accommodate up to 10000 additional ICU admissions per year.

\section{SPECIAL AREAS OF INTEREST}

While there is an emphasis on the practicalities of providing NIV, some important aspects of ICU management are included and both ventilator 'weaning' and the 
extended applications of NIV are considered in the light of evidence that has accumulated in recent years. For instance, NIV may shorten the duration of weaning and be used to manage postextubation respiratory distress. The guideline recommends that a trial of extubation, with NIV support in the postextubation period, should be preferred before the insertion of a tracheostomy in many AHRF patients. The outcome of the currently recruiting BREATHE trial, investigating early extubation onto NIV, will also inform clinical practice in this area. ${ }^{11}$ Finally, the guideline recommends that survivors with potentially reversible chronic hypercapnia should be referred to a regional home ventilation centre as prolonged survival, with an acceptable quality of life, is generally possible in muscular dystrophy and in patients with chest wall deformity and complete reversal of respiratory and cardiac failure may follow bariatric surgery in the obesity hypoventilation syndrome.

\section{THE NEXT STEP...}

There is clearly a need for guidance on providing an integrated service in the management of AHRF and this guideline usefully points to areas where more evidence is required. The immediate target audience is medical, nursing and physiotherapy staff working in emergency receiving rooms, medical assessment units, admission wards, respiratory wards and high dependency and critical care units. If the guideline is to make a difference, and improve both patient experience and outcome, a national dialogue will be needed between representatives of intensive care, respiratory medicine and acute care. The guideline recommends that hospitals should appoint a senior physician to lead in the coordination of care in AHRF. Rolling programmes of staff training will be needed to improve and maintain standards and auditing performance will be critical in improving the quality of care. The BTS NIV audit tool can help, and even increase resources ${ }^{2-4}$ but, as it only identifies cases referred for treatment, it currently underestimates the incidence of AHRF. Hospital governance and risk management could provide much needed leverage for change. Indeed, episodes of oxygen toxicity, unexpected death while on NIV or a high NIV failure rate should be reported and regularly reviewed. We acknowledge that effecting an improved service for patients will take time and further resource will be needed. Most importantly, it will require the energy of enthusiasts to drive change. Without this, the human cost of not implementing the guidelines will remain considerable.

Contributors $A C D$ is the author of the editorial and responsible for its content and final approval.

Competing interests $A C D$ declares being paid as a consultant to Smith Medical between 2008 and 2013.

Provenance and peer review Commissioned; internally peer reviewed.

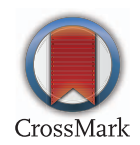

To cite Davidson AC. Thorax 2016;71:297-298.

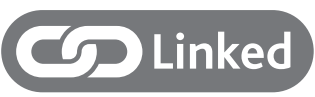

http://dx.doi.org/10.1136/thoraxjnl-2015-208209
Thorax 2016;71:297-298.

doi:10.1136/thoraxjnl-2016-208281

\section{REFERENCES}

1 Roberts CM, Stone RA, Buckingham RJ, et al. Acidosis, non-invasive ventilation and mortality in hospitalised COPD exacerbations. Thorax 2011;66:43-8.

2 Lobo AJ, Greenfield AM, Forgacs I. Deficiencies in services for acute upper gastrointestinal bleeding. BMJ 2015;351:h4774.

3 Davidson AC. Report British Thoracic Society NIV Audit Report 2011. https://www.brit-thoracic.org.uk/ audit-and-quality-improvement/bts-audit-programmereports/

4 Davies M. Report British Thoracic Society NIV Audit Report 2012. https://www.brit-thoracic.org.uk/auditand-quality-improvement/bts-audit-programmereports/

5 Davies M. Report British Thoracic Society NIV Audit Report 2013. https://www.brit-thoracic.org.uk/auditand-quality-improvement/bts-audit-programmereports/

6 National Audit: COPD Who cares? 2014. https:// www.rcplondon.ac.uk/sites/default/files/national copd_secondary_care_organisational_audit_2014_ national_report_web.pdf

7 Plant PK, Owen JL, Elliott MW. Early use of noninvasive ventilation for acute exacerbations of chronic obstructive pulmonary disease on general respiratory wards: a multicentre randomised controlled trial. Lancet 2000;355:1931-5.

8 Wildman MJ, Sanderson C, Groves J, et al. Implications of prognostic pessimism in patients with chronic obstructive pulmonary disease (COPD) or asthma admitted to intensive care in the UK within the COPD and asthma outcome study (CAOS): multicentre observational cohort study. BMJ 2007;335:1132.

9 Wildman MJ, Sanderson CF, Groves J, et al. Survival and quality of life for patients with COPD or asthma admitted to intensive care in a UK multicentre cohort: the COPD and Asthma Outcome Study (CAOS). Thorax 2009;64:128-32.

10 Etheridge Z, Gatland E. When and how to discuss "do not resuscitate" decisions with patients. BMJ 2015;350:h2640.

11 ISRCTN 15635197 Protocolised trial of invasive and non-invasive weaning off ventilation-the BREATHE study. 
Erratum: 'British Thoracic Society Guideline Group For The Ventilatory Management of Acute Hypercapnic Respiratory Failure in Adults. Managing acute hypercapnic respiratory failure in adults: where do we need to get to?'

Davidson AC. British Thoracic Society Guideline Group For The Ventilatory Management of Acute Hypercapnic Respiratory Failure in Adults. Managing acute hypercapnic respiratory failure in adults: where do we need to get to? Thorax 2016;71:297-8.

Correspondence information for this paper should be the following:

Dr A Craig Davidson, British Thoracic Society, 17 Doughty Street, London WC1N 2PL, UK; craigdavidson@doctors.org.uk

Thorax 2016;71:492. doi:10.1136/thoraxjnl-2016-208281 corr1

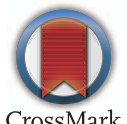

CrossMark 